\title{
IFCXML Based Automatic Data Input Approach for Building Energy Performance Analysis
}

\author{
Karam $\mathrm{Kim}^{1}$ and Jungho $\mathrm{Yu}^{2}$
}

Accepted February 1, 2013

\begin{abstract}
To analyze building energy consumption, the building description for building energy performance analysis (BEPA) is required. The required data input for subject building is a basic step in the BEPA process. Since building information modeling (BIM) is applied in the construction industry, the required data for BEPA can be gathered from a single international standard file format like IFCXML. However, in most BEPA processes, since the required data cannot be fully used from the IFCXML file, a building description for BEPA must be created again. This paper proposes IFCXML-based automatic data input approach for BEA. After the required data for BEPA has been defined, automatic data input for BEPA is developed by a prototype system. To evaluate the proposed system, a common BIM file from the BuildingSMART website is applied as a sample model. This system can increase the efficiency and reliability of the BEPA process, since the data input is automatically and efficiently improved by directly using the IFCXML file.
\end{abstract}

Keywords: Building Information Model; IFCXML; Building Energy Performance Analysis; Data Input Approach

\section{INTRODUCTION}

Along with global awareness of green building, there is a growing interest in building energy performance analysis (BEPA). Building energy analysis is necessary for analyzing building performance and Building Information Modeling (BIM) technology is becoming increasingly valuable in architecture. Use of BIM for green projects is expected to grow dramatically in the short term $78 \%$ of BIM users not currently using BIM for green projects will be doing so within three years [1].

Most architecture for designing buildings imports a model using BIM-based industry foundation class (IFC) standard file format. Since 1994, IFC has been a standard data set for the international alliance for interoperability (IAI). It is frequently used in BIM-based computer programs. Using IFC without STEP technology, however, data parsing and processing become complex [2]. In addition, using STEP technology makes it difficult to systematically read and write building information. To that end, IFC can be converted into extensible markup language (XML) as the industry foundation class extensible markup language (IFCXML) file format. The IFC file can also be changed into IFCXML using XML. IFCXML is a standard format developed by IAI in 2007. The current release, IFCXML $2 \times 3$, was developed using the same rules and configurations as the IFCXML $2 \times 2$ release. The basic structures of IFCXML are based on the IFCXML schema [3], and the elements and attributes of the IFCXML schema are derived from the standard IFC schema. The IFCXML schema is easier to use on the web than the IFC schema.

The most popular BEPA engines are DOE-2 and EnergyPlus. However, those BEPA engines have no capability to import IFC files. Thus, users who want BEPA using BIM, must change the model's file format from IFC to native file format INP file on the DOE-2 engine and IDF file on the EnergyPlus engine. This can lead to potential problems when adopting BIM for BEPA. The first is limitation of data interoperability between computer aided design (CAD) and BEPA programs. BIMbased information transfer should be seamless, and data transfer should occur without loss of information [4]. In addition, many BEPA programs require specific information which makes difficult to analyze building energy performance in the conceptual design phase. When users input specific information into BEPA programs, subjectivity can become an issue. Furthermore, since there are many stakeholders in a construction project, it is hard to define who should create the data or when the data should be created. Mistakes can occur in the data input process, decreasing the accuracy and reliability of the BEPA.

To solve these problems, this paper proposes an IFCXML-based automatic data input approach for BEPA. After the required data for BEPA have been defined according to BuildingSMART specification, the data are extracted from IFCXML to use for data input. In addition, the methodology and form are developed to input data by a web-based prototype system.

\footnotetext{
${ }^{1}$ PhD Student, Department of Architecture Engineering, Kwangwoon University, Seoul, Korea, karamiz@kw.ac.kr

${ }^{2}$ Associate Professor, Department of Architecture Engineering, Kwangwoon University, Seoul, Korea, myazure@kw.ac.kr ( ${ }^{*}$ Corresponding Author)
} 
This paper considers a DOE-2 based BEPA process, which is limited to calculating the building energy load. In addition, IFCXML $2 \times 3$ schema is used to create a building model. To develop the proposed system, three flowcharts of sub-systems were defined considering both of user process and data process. The proposed system will ensure the data input process to make more efficiently and more accurately than current practice for BEPA. Finally, since the cycle time of BEPA process can be short on the early design phase, the whole design process will be effective.

\section{REVIEW OF CURRENT DATA INPUT APPROACH}

\section{A. Current practice of BEPA process}

As building energy performance is becoming increasingly important, BEPA tools have been developed to measure building energy consumption. Most BEPA tools include a simulation engine for detailed building energy simulations and require simple text-based input and return output files in the same text format, including peak loads, monthly loads, and used energy costs. One of the most widely used engines is DOE-2 [5].

To implement an energy simulation engine, a building model is required in the design phase. Without BIMbased building modeling, required data for BEPA must be input manually even though representation data was created in the design phase. This leads to several potential problems. For instance, when required data is input, some data may be missing or input incorrectly. Moreover, it is unclear who is responsible for missing data. When the BEA is initiated, the required data must be collected from each different source to become part of the building description. In the BIM-based BEPA process, importing model and inputting properties data procedures can be automated by BIM technology. Figure 1 shows both BEPA and BIM processes.

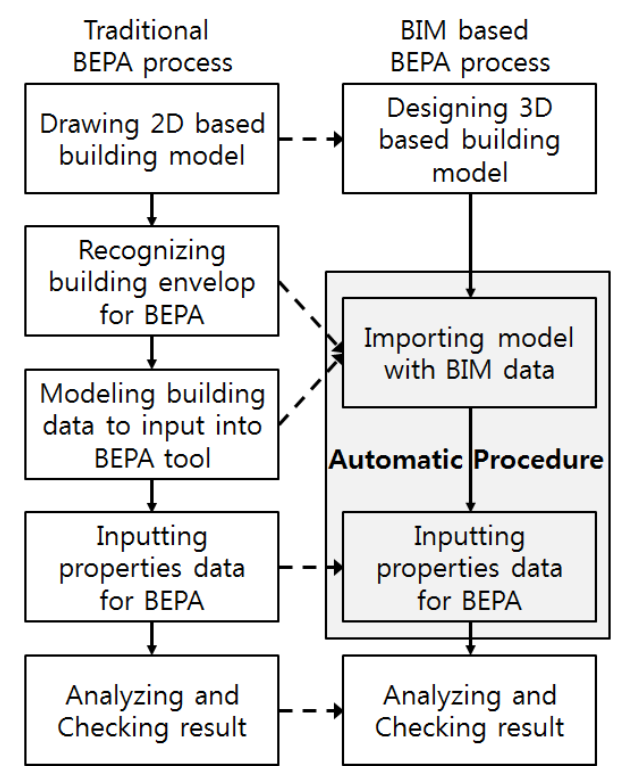

FIGURE I

BOTH PROCESSES OF BEPA
Many researchers have studied the input of information for BIM-based data input for BEA. Oh et al. proposed a method using a genetic algorithm and Pareto optimality to determine the optimal design for a green building [6]. Sullivan and Keane proposed a graphical user interface to input the data of an HVAC system into BIM-based building energy simulation using an IFC file [7]. Kim et al. suggested the necessary steps to develop the data mining approach with a case study of an ongoing design project [8]. Bazjanac describes the methodology and interoperability of IFC-based BIM and BEPA tools [9]. In this methodology, geometry data and HVAC data are reused in EnergyPlus for building energy analysis.

Most studies have considered data exchange between 3D-CAD and BEA tools in the BIM-based BEPA process. Currently, the required data for BEPA already exists in BIM-based standard file formats, such as IFC and gbXML. In this regard, gbXML has some limitations in the BEPA process, since it must design a specific design tool, such as Ecotect or Revit MEP, by a BEPA specialist. In addition, each composite material must be divided by a single unit of material.

\section{B. Required data for BEPA}

BEPA is concerned with predicting the usage profile and cost of energy consumption within buildings [10]. As shown in Table 1, various types of data are required, such as project, site, site context, building, energy target, building stories, spaces, thermal comfort criteria, ventilation criteria, ventilation design, second-level space boundaries, building elements, material, and energy analysis zone [11]. As shown in Figure 2, this required data can be categorized by input method: automatic extraction (hereinafter data (A)) and manual input (hereinafter data $(\mathrm{M})$ ). Some required data are extracted from a BIM file as data (A) such as building storey, building elements, and materials, whereas other data are input manually as data (M) such as energy target and thermal comport criteria. In addition, required data can be grouped by principle agent to create and manage the data as project, space, and material.

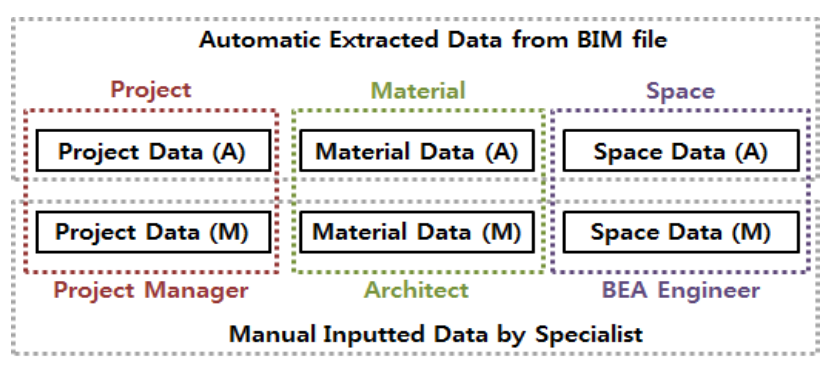

FIGURE II

REQUIRED DATA CATEGORY

The required data can be categorized according to type. As mentioned, there are three types of required data: project, space, and material. Initially, project data describe the general conditions of building. Project data include location, building type (e.g., office, residence, and hospital), and building operation. The second type is 
space data, which describe strategy of usage types of the building. It contains building storey, thermal comfort criteria, and ventilation criteria. The third type is material data, which consists of building elements and materials. Building elements are included not only in building elements (e.g., wall, slab, roof, window, door) but also in thermal properties (e.g., thermal resistance, solar heat gain coefficient). Materials include data about layers and layer sets, which are made up of a set of materials. This also contains thermal properties, such as roughness, density, specific heat and so on.

TABLE I

REQUIRED DATA FOR BEPA

\begin{tabular}{|c|c|c|c|}
\hline Category & Required data & Description & Examples \\
\hline \multirow{3}{*}{ Project Data (M) } & Project & Define general data to identify the specific project & Owner/Client Information \\
\hline & Site & Where the subject building is located & Building Address \\
\hline & Energy Target & Set the energy target values with its unit to analysis & $\begin{array}{l}\text { Energy Target Units } \\
\text { Energy Target Value }\end{array}$ \\
\hline \multirow[b]{2}{*}{ Project Data (A)z } & Site Context & Existing buildings adjacent to the subject building & 3D Geometry \\
\hline & Building & Define general data to identify the specific building & $\begin{array}{l}\text { Identification } \\
\text { Orientation }\end{array}$ \\
\hline \multirow{4}{*}{ Space Data (M) } & $\begin{array}{l}\text { Thermal } \\
\text { Criteria }\end{array}$ & $\begin{array}{l}\text { Define the temperatures required in a space for heating } \\
\text { and cooling }\end{array}$ & $\begin{array}{l}\text { Dry bulb temperature } \\
\text { Relative humidity }\end{array}$ \\
\hline & Ventilation Criteria & Set the requirements for ventilation in a space & $\begin{array}{l}\text { Designed quantity of outside air to } \\
\text { be provided }\end{array}$ \\
\hline & Ventilation Design & Set the results for ventilation design in a space & $\begin{array}{l}\text { Whether a ceiling plenum is to be } \\
\text { used }\end{array}$ \\
\hline & Energy Analysis Zones & $\begin{array}{l}\text { Type of zone, all spaces in the building must be assigned } \\
\text { to only one energy analysis zones }\end{array}$ & $\begin{array}{l}\text { Zone type } \\
\text { Infiltration rate }\end{array}$ \\
\hline \multirow{3}{*}{ Space Data (A) } & Building Storey & Stories that make up the building & Stories, Elevation \\
\hline & Space & Define the spaces to use by people & $\begin{array}{l}\text { Space Usage } \\
\text { Occupancy Schedule }\end{array}$ \\
\hline & $\begin{array}{ll}\text { Second Level } & \text { Space } \\
\text { Boundaries } & \\
\end{array}$ & Relationship between space and element & $\begin{array}{l}\text { Space boundary type } \\
\text { Link to building element }\end{array}$ \\
\hline Material Data (M) & Material Property & Attributes of material & $\begin{array}{l}\text { Thickness, } \\
\text { Thermal conductivity }\end{array}$ \\
\hline \multirow{2}{*}{ Material Data (A) } & Building Element & $\begin{array}{l}\text { Set the components such as wall, slab, roof, floor, } \\
\text { window, and door }\end{array}$ & $\begin{array}{l}\text { Building element type } \\
\text { Link to Material }\end{array}$ \\
\hline & Material & $\begin{array}{l}\text { A building material including material layer and material } \\
\text { layer set }\end{array}$ & Material name \\
\hline
\end{tabular}

\section{IFCXML-BASED AUTOMATIC DATA INPUT APPROACH}

\section{A. Overall system architecture}

To develop an automatic BEPA data input approach, there are three sub-systems: 1) IFCXML data parsing system, 2) BEPA data input system, 3) automatic BEPA system. The first sub-system is the IFCXML data parsing system, which extracts the IFCXML data and adds the properties for BEPA to the used material data with elements. The second sub-system is the BEPA data input system. It is the most important part of the proposed system. It assists manual data input for BEPA process, such as schedule of operation, building type, building location, and quantity of heat gain for each space using default library DB. In this regard, extracted data from the IFCXML file (e.g. project data (A), space data (A), and material data (A)) become basic information for additional input data. The last sub-system is the automatic BEPA system. It contains a DOE-2 engine based BEPA process. Using input data from previous sub-systems, it can automatically create an INP file, which is an input file format for the DOE-2 simulation engine. In addition, the result of BEPA is shown as summary data.

\section{B. Data (A) extraction system}

In the IFCXML file, since there are so many data to describe a subject building, specific extracting data should be defined by entity and relationship of data. In the proposed system, the entities of extracted data (A) are defined by three types: project data (A), space data (A), and material data $(\mathrm{A})$.

In addition, element data, which contain material data (A), has a relationship with space boundaries. Through this relationship, the system can recognize what material is used in an element. According to the algorithm of the IFCXML data parsing system, after the IFCXML file has been uploaded, the system parses space boundaries to recognize what elements are organized in a space. Then, material data (A) can be matched to an element. In this regard, the properties of each material (e.g. density, conductivity, and specific heat) are input to material by the material name. After matching the properties, the extracted data are stored in project temporary DB. Figure 3 shows the process of data (A) extraction from the IFCXML file. 


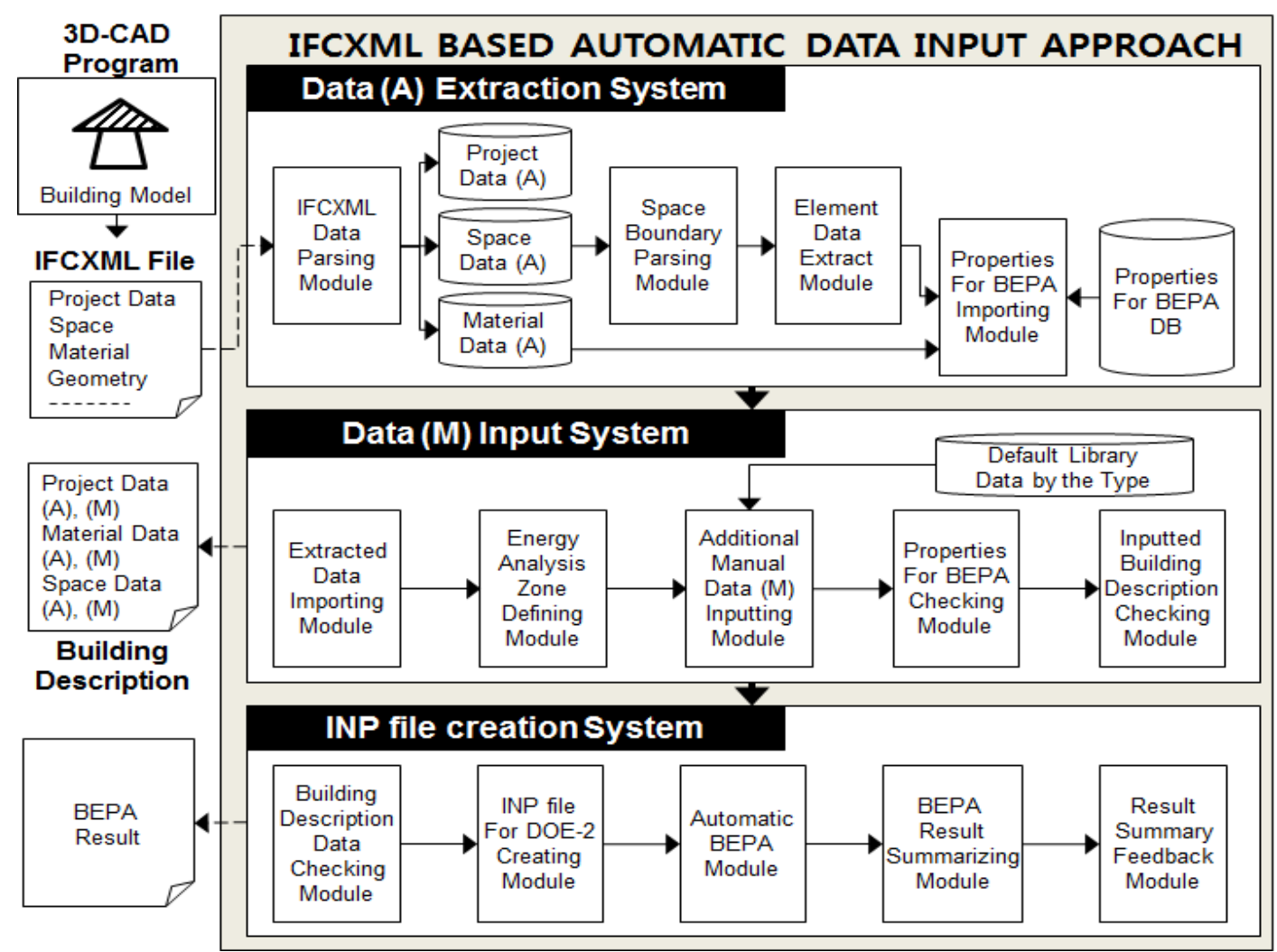

FIGURE III

OVERALL SYSTEM ARCHITECTURE

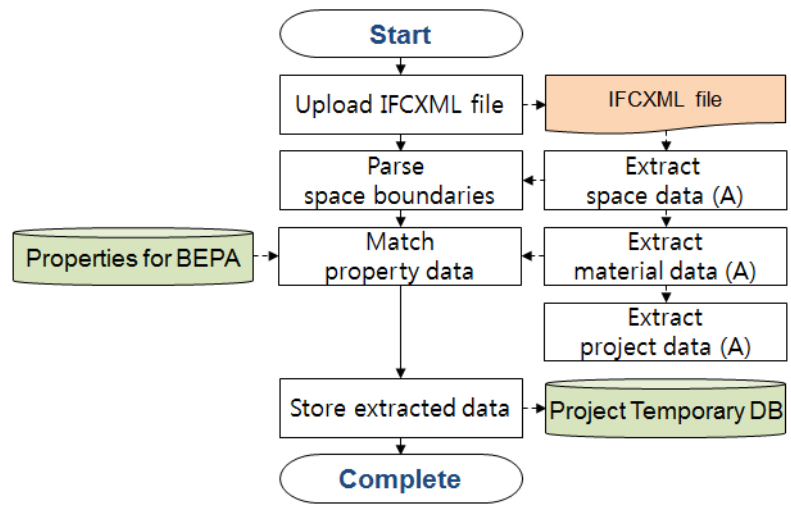

FIGURE IV

DATA (A) EXTRACTION PROCESS

\section{Data (M) input system}

This sub-system is used to input BEPA data (M) by the proposed system. First, the user must access the system by their ID, since the project list must remain private. After creating a new project, the IFCXML file must be to uploaded. In this regard, extracted project data (A) supports input project data (M) (e.g. schedule, location, and weather). Then, an energy analysis zone can be set based on the space data (A) extracted by the user. In this

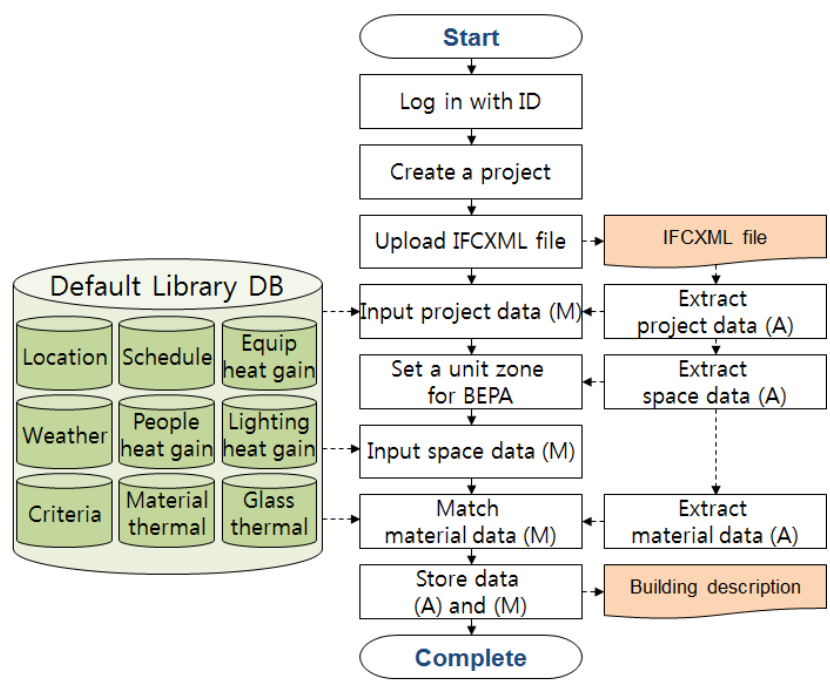

FIGURE V

DATA (M) INPUT PROCESS

regard, since the space list is extracted from the IFCXML file, the user can group the selected spaces by usage. Then, space data $(\mathrm{M})$ is manually inputted based on space data (A). Finally, after all data (A) and (M) have been stored in the project temporary DB to create a building description, the BEPA data input process is complete.

\section{Automatic BEPA system}

The final sub-system is the automatic BEPA system. 
Since the building description has been input by the previous systems, the user can just check if the data are correct. After checking the building description, the system automatically creates an INP file. It is necessary to convert the data format from IFCXML or project temporary DB to the INP file. This takes about 10 seconds depending on the file size. After creating the INP file, it is automatically entered into the BEPA module weather data file (BIN file) is also input to BEPA module automatically by the location of the building. The next steps follow the DOE-2 based BEPA process. The result is summarized by the system, and the table of energy performance is converted into graphical images.

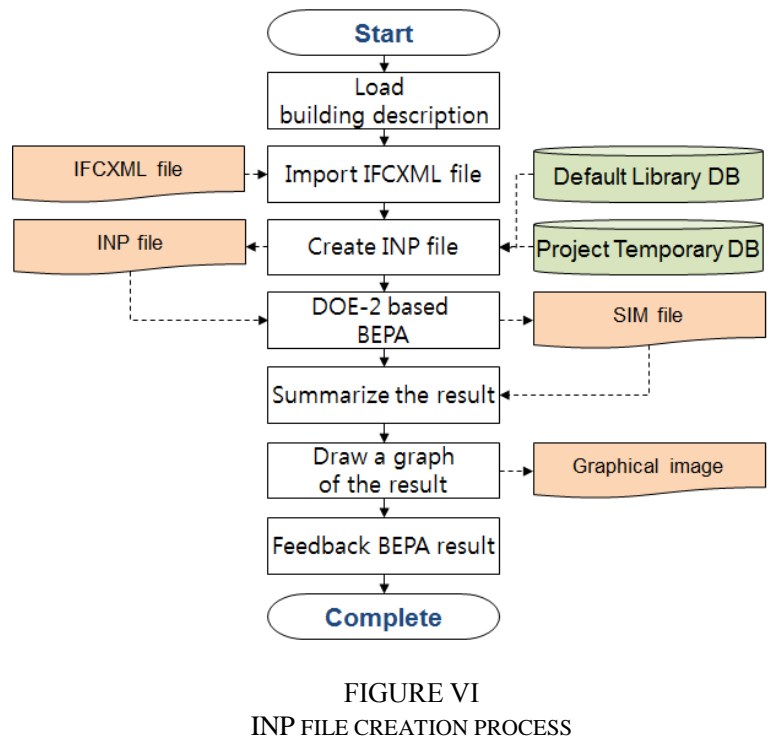

\section{EVALUATION}

To evaluate the proposed system, a sample building model, 'Duplex A 20110907', is referenced from the BuildingSMART website 1. It is a common BIM file used to evaluate a BIM-based developed system. The sample model has 2 stories and 19 spaces with space boundary information. Figure 7 shows about the architecture of sample model.
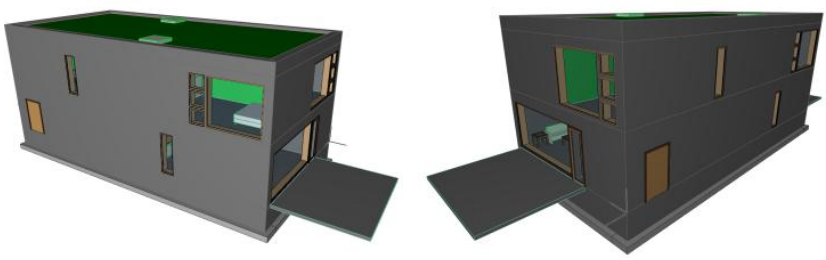

FIGURE VII

SAMPLE MODEL FROM A COMMON BIM FILE

Since the proposed system was developed through integrated sub-systems, the IFCXML file was uploaded only once time at the beginning of the evaluation. In addition, extracted data from IFCXML file were shared

\footnotetext{
${ }^{1}$ http://buildingsmartalliance.org/index.php/projects/ commonbimfiles/ available at 2012.09. 30.
}

into an integrated system, so the extracting process can be omitted except at the beginning of the evaluation. The steps for evaluation follow (Figures 8 and 9):

Step 1: Create a new project to input data for BEPA.

Step 2: Upload the IFCXML file.

Step 3: Set energy analysis zone using extracted space list from the IFCXML file.

Step 4: Input data $(M)$ on the system based on the extracted data from IFCXML file using default library DB.

Step 5: Match the thermal properties of default library and material (A) for each element including doors or windows.

Step 6: Create INP file automatically based on input building description.

Step 7: Implement DOE-2 based BEPA using created INP file.

Step 8: Draw the summary of BEPA result by graphical image.

Since the IFC schema is not intended to store and carry all relevant data for the BEPA process [12], some information must be input into the system by users. However, default library DB is applied for convenient manual data input. In the default library DB, there are sets of pre-defined data for BEPA, such as schedules of each building type, geometry data of location, and heat gain of each type. In addition, most processes are developed automatically and systematically, making them simple and objective.

To compare the proposed (automatic) and current approach (manual), BEPA processes are defined by data input method. In the current approach, the IFC-based sample model must be exported to a 2D-based floor plan to recognize the building data by user. After the required data are collected from the 2D-based building model, they can be input into the eQEUST program. Each required data must be input one by one manually. Then, BEPA can be implemented by eQEUST program. However, since the eQUEST program is not only used for BEPA, there are additional data required to analyze building energy performance, such as the HVAC system. In this regard, a specialist's opinion is necessary for additional data.

However, the proposed system can be implemented without additional data. Since the extraction of BIM data from IFCXML, the input of property data, and the analysis of building energy performance run automatically, the cycle time of the BEPA process is dramatically reduced. Figure 10 shows the comparison of both approaches with screen-shots of the BEPA process. On the current approach, manual procedures must be input data in series using the BEPA tool, such as eQUEST program. On the other hand, the proposed approach can input data automatically and systematically using the BIM-based proposed system. 


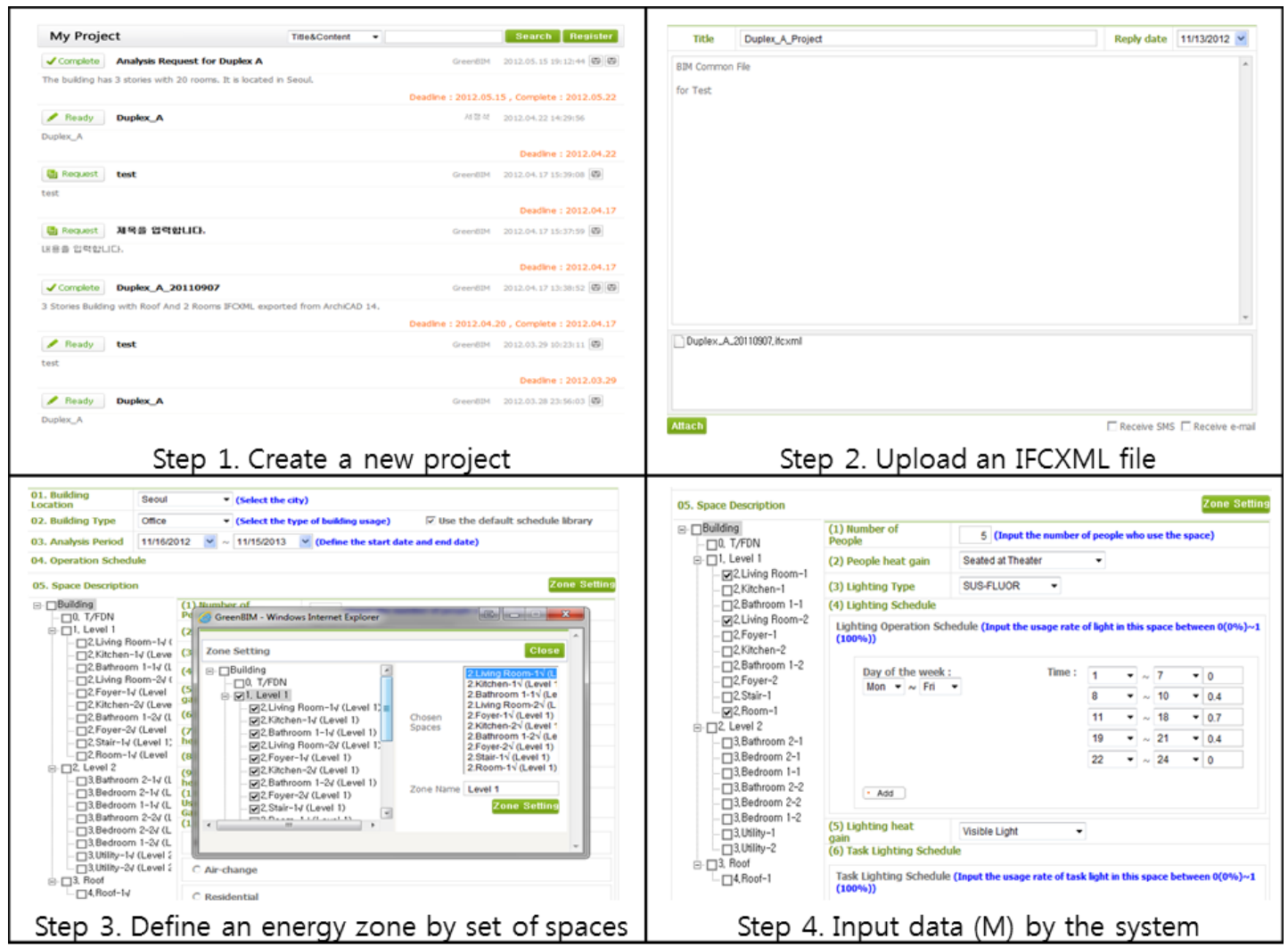

FIGURE VIII

EVALUATION PROCESS BY 1 TO 4 STEPS

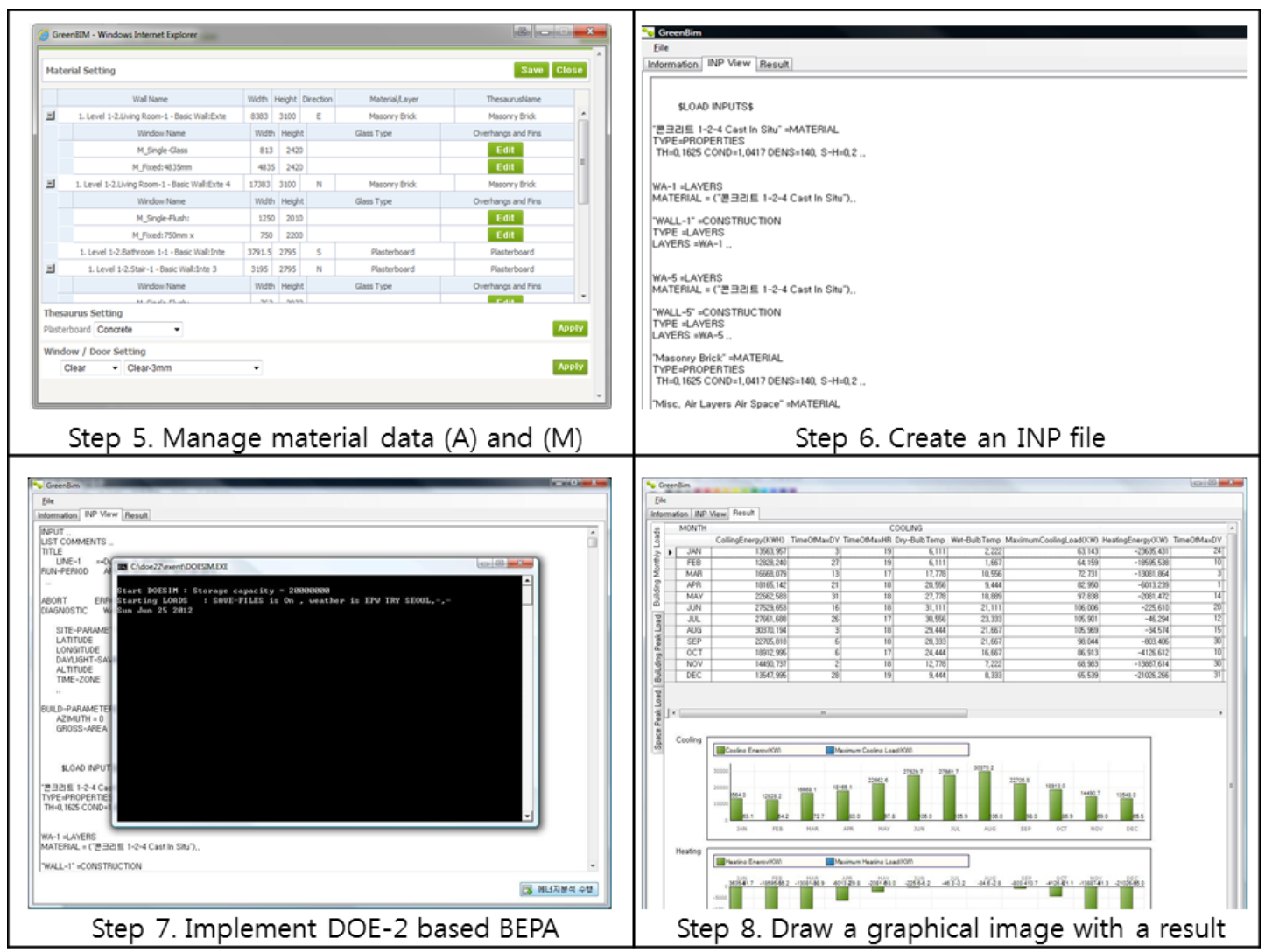

FIGURE IX

EVALUATION PROCESS BY 5 TO 8 STEPS 

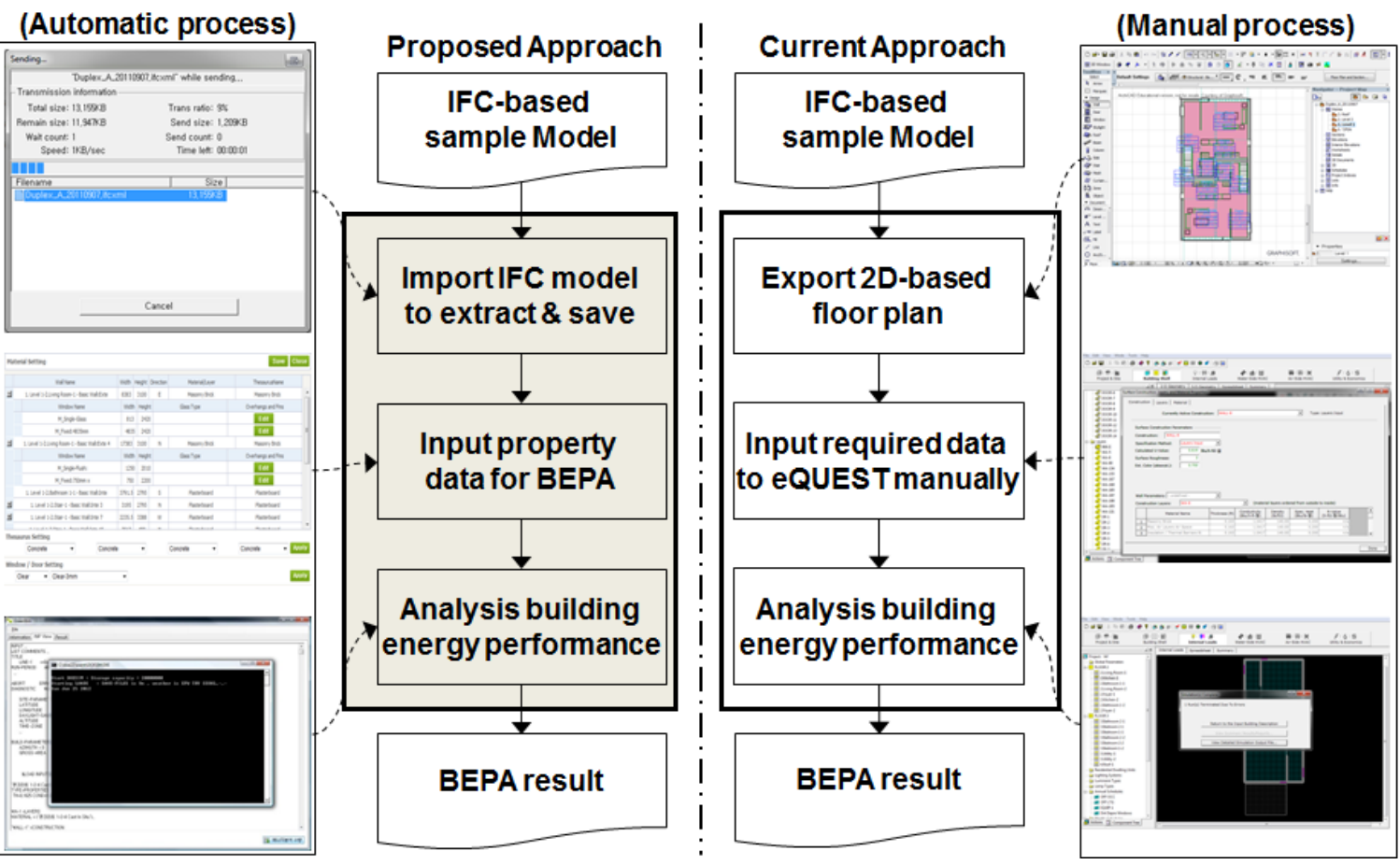

FIGURE X

COMPARISON OF BOTH APPROACHES

\section{CONCLUSION}

BIM technology has already been adopted in the AEC industry using IFC/IFCXML file format for various projects. The BEPA process, however, is currently inefficient due to the manual data input required for writing building descriptions and creating INP files. Since the BEPA process takes a long time to obtain a feedback for alternative design, the time and cost of the project is increased. This paper proposes IFCXML-based automatic data input for building energy performance analysis. The system has three sub-systems: 1) IFCXML data parsing system, 2) BEPA data input system, and 3) automatic BEPA system. In addition, the required data for BEPA is categorized by input method and type: project, space, and material. The extracted data from IFCXML file is defined as automatic or manual. Evaluating the proposed system using a common BIM file from the BuildingSMART web-site, we show that the proposed system can be easily implemented.

This approach will enable architects and engineers involved on a BEPA process to input required data easily and automatically using IFCXML standard file format. Consequently, this approach can contribute to increasing the efficiency and the objectivity of the BEPA process. In addition, since the proposed approach can reduce the invested cost and time for BEPA, the result is considered more frequently to design various alternatives during the design phase.

Future research should further evaluate more complex building models, including free-form design. In addition, the default library must be adapted to any religion or criteria of international standard, and heating, ventilation and air conditioning (HVAC) information should be considered for the BEPA process in proposed system.

\section{ACKNOWLEDGEMENTS}

This work was supported by the National Research Foundation of Korea (NRF) grant funded by the Korea government (MEST) (2012-0005376)

Note: This paper was originally published as the conference paper in the ICCEPM 2013 and awarded as one of the best papers. Through a rigorous review process, the paper has been invited to be a special version of JCEPM.

\section{REFERENCES}

[1] McGraw Hill Construction, "GreenBIM Smart market report", 2010.

[2] E.F. Begley, M.E. Palmer, K.A. Reed, "Semantic Mapping Between IAI ifcXML and FIATECH AEX Models for Centrifugal Pumps", Building Environment Division Building and Fire Research Laboratory, National Institute of Standards, U.S. Department of Commerce, and Technology Administration, 2005.

[3] L. Thomas, "IFC 2x Edition 3, Model Implementation Guide", BuildingSMART international modeling support group, Version 2.0, 2009.

[4] S. Kumar, "Interoperability between building information models and energy analysis programs", In Partial Fulfillment of the Requirements for the degree master of building science, 2008.

[5] T. Maile, M. Fischer, V. Bazjanac, "Building Energy Performance Simulation Tools - a Life-Cycle and Interoperable Perspective", Stanford University, CIFE Working Paper \#WP107, 2007.

[6] S. Oh, Y. Kim, C. Park, I. Kim, "Process-driven BIM-based optimal design using intergration of energyplus, genetic algorithm, and pareto optimality", Proceedings of the 12th conference of 
international building performance simulation association, Sydney, Australia, pp. 894-901, 2011.

[7] B. O'Sullivan, M. Keane, "Specification of an IFC based intelligent graphical user interface to support building energy simulation", Proceedings of the 9th international building performance simulation association conference, Montreal, Canada, pp. 875-881, 2005.

[8] H. Kim, A. Stumpf, W. Kim, "Analysis of an energy efficient building design through data mining approach", Automation in construction, vol. 20, no. 1, pp. 37-43, 2011.

[9] V. Bazjanac, "IFC BIM-based methodology for semi-automated building energy performance simulation", Lawrence Berkeley National Laboratory, 2008, Available at http://escholarship.org/uc/item/0m8238pj.

[10] L. Swan, V. Ugursal, "Modeling of end-use energy consumption in the residential sector: A review of modeling techniques", Renewable and Sustainable Energy Reviews, vol. 13, no. 8, pp. 1819-1835, 2009.

[11] US GSA, "Information Delivery Manual for BIM based energy analysis as part of the concept design BIM 2010", Building SMART MVDs, Ver. 1.0, 2009.

[12] S. Fuchas, P. Katranuschkov, R.J. Scherer, "A framework for multi-model collaboration and visualization", Proceedings of the 8th European Conference on Product and Process Modeling, University of Cork, Ireland, pp. 115-124, 2010. 